\title{
Narrative, Genre and Context in Popular Science
}

\author{
LisA GJEDDE
}

There is no story that is not embedded in other stories. Fisher: "Narration, Reason and Community." Suny 1997

\section{Genre, Story and Knowledge}

Popular Science as a genre scaffolds a set of expectations and hypothesis the audience holds, one of them being that what they read about deals with fact not fiction. The readers are able to explicate some of this knowledge as stories about what their expectations are and according to cognitive psychologist Roger Schank such knowledge is stored and also serve as indices to stories. So genre and story are two concepts that interrelate closely, when it comes to exploring how genre functions on a cognitive level and looking at its qualities within a framework of cognitive theories and models that deals with schemas, scripts and stories. (Schank 1990; Huckin 1995)

"Genres are intellectual scaffolds on which community-based knowledge is constructed" (Huckin 1995) Berkensdotter \& Huckin use this definition of genre in disciplinary communications where they are dealing with genre from a socio-cognitive perspective.

It points to the cognitive importance and impact of genre. Seeing stories as fundamental to scaffolding knowledge (Schank 1990), one might raise the question if this cognitive concept of genre implies genre as comprising some of the stories within which other stories are imbedded? How does it relate to qualities like comprehension, relevance and

Research Centre for Educational HCI, Royal Danish School of Educational Studies, Roskilde University, Box 260,DK-4000 Roskilde,lg@dlh.dk credibility, and how are the narrative responses, that serve to generate meaning, to the different genres?

What are the cognitive implications of the genre that is inscribed through textual elements? What are the readers criteria for how they perceive the credibility of the articles?

How can it be related to the readers situated cognition, to their background and gender, to their personal contexts and how can it be seen reflecting in their retellings?

This present article undertakes to look at a few of these issues in particular those dealing with gender and the readers comprehension of the gist of articles in relation to level of narrative, and how relevance and credibility is perceived and constructed.

\section{Genre and Situated Cognition}

In line with this approach is the idea that "genre knowledge is a form of "situated cognition" (Brown, Collins \& Duguid, 1989) that continues to develop as we participate in the activities of the ambient culture." (Huckin 1995)

The genre of Popular Science is wide, as (Shinn 1985) Shinn and Cloître defines it, though they do not reflect on narrative as a format for it. It consists of a continuum, rather than clearly demarcated stylistic markers. One of the markers Shinn and Cloître points to, the imagery, have together with emotive language and narrative structure been variables in a reconstruction of 4 articles from a popular science magazine, that forms the corpus of this research together with the retellings and qualitative interviews by the 16 participants. These articles are rewritten to depict subtle changes of the narrative form within the genre of a Popular Science magazine ranging from full narrative to encyclopaedic style texts. 
The subtle levels of genre, or micro-levels might only be perceptible to the readers when exposed to the same article in different versions as I did in the pilot version of this study. The final design employing different versions in the different articles did not make these shifts and manipulations immediately transparent to the readers. Nonetheless differences in the retellings and the narrative involvement of the reader indicate that their responses to the different levels of narrative were both influenced by the level of narrative and their previous knowledge about the topic, which other stories they had to draw upon to create relevance. To the extent of having little previous knowledge, no education or not many stories of ones own to draw upon, it was more important with the higher level of narrative in the magazine to draw upon.

Using the term micro-levels of genre is not implying a hierarchy as such. But it does refer to the way that the constituents ranging from narrative level to topic to genre interrelates and affects the perceptions of the informant. The findings indicate that preference for topic overrides preference for level of narrative. And also that the individual informants construction of and expectations to the genre of popular science varies according to personal habitus.

\section{Narrative, Context and Relevance}

Narrative is very prominent in the media, it is at play not only in fiction but it is also used in documentary and drama-documentary, it is studied and employed in a wide array of genres ranging from full-fledged fiction to providing the structure of an otherwise dry documentary. There is a continuum which moves from a full-blown fiction film (Branigan 1992) to the underlying narrative structure in Scientific discourse. (Greimas 1990)

Narrative has traditionally been a popular format for transmission of knowledge, and for using the stories for insight and transformation. The parables of the Bible and the stories from the Arabian Night are examples of the great diversity. Jesus and Scherazade were both highly skilled storytellers and their narratives served the enlightenment of their listeners even in very different universes.

Folktales have traditionally been receptacles of knowledge and wisdom; Analytical psychologists like Jung, (Franz 1970) and Bettelheim (Bettelheim 1984) have uncovered some levels of it. Another cognitive level has been at the focus of work in experimental psychology (Bartlett 1932, 1995) struc- turalism (Propp 1968, 1928; Greimas 1990; Mandler 1984), where the focus has been on constructing models for a storygrammar. Another avenue of structural modelling has been done in the sociolingvistic work of Labov and Waletzsky (Labov 1967, 1997).

This has resulted in a number of studies focusing on the linguistic levels but not on the contextual levels. Thus not addressing the levels of narrative construction at the level where it deals with the process not just of structuring information but also how the structure interacts with the readers other stories, or storied information (borrowing the term storied from Sarbin). (Sarbin 1986) This level has to do with personal and cultural context and with the construction of relevance. This construction of relevance has to do with what could be termed the reader's superthemes. Or the basic or fundamental or guiding beliefs of the person.

In this connection there is a situatedness of the narrative which refers to the use of narrative to embed the information in a narrativized context, and thus to create a link to sensed reality. A reality, which can be visualised and photographed and transformed into human interactions or human projections on animals, stars, natural phenomena of any kind and which conforms to some basic narrative traits.

\section{Aim of the Study}

This study is based on exploring the use of narrative in applied communications, through an empirical study of a popular science magazine. Through an experimental design, the readers interaction with process of narrative comprehension and construction are explored; how they make sense of the material according to gender and background. Also their preferences and reading strategies, by presenting the readers with a number of reconstructed articles, each representing a particular aspect of a narrative continuum. Through the experimental reception method (Ingemann 1998, Gjedde \& Ingemann 1999) a number of parameters are activated which removes the situation from the mere exchange of opinions of the informant, to another dimension that calls for the action of the informant. This action is taking place at several levels, which makes it possible to interpolate them. To create a triangulation of the data thus elicited by the informant's retellings, interviews and ratings of the articles. It is then possible to use them to clarify and enlighten certain aspects, which call for a different level of analysis 
than the level of data obtained through mere answering of questions allows for.

\section{Background and Scope for the Study}

Applied Communications is an academic discipline based on the communication of science and subjects of public interest, to a wide, often naïve audience, within a variety of media and often based on careful analysis of the potential target groups. Seen from the point of view of that discipline, it is of importance and of interest to monitor just how the readers go about constructing meaning and making sense of different types of text in order to properly evaluate the use of narrative in this area.

How the readers perceive the credibility of the texts and how they become interested, involved and perceive relevance.

Another motivation is to add empirical knowledge to the construction of a viable production theory for the field.

\section{Methodology}

This study attempts through application of experimental reception methods (Gjedde \& Ingemann 1999) to examine the interplay between reader, text and context in a popular science magazine. The variables used are 4 actual articles from this magazine in the original version plus 3 reconstructed versions, altogether comprising 16 articles with varying degrees of narrative language. These articles are grouped into 4 sets and presented to a panel of 16 natural readers of this magazine, selected on the basis of a questionnaire that was distributed to 300 randomly selected subscribers, with an equal distribution between male and female subscribers. The only criterion being that they had been subscribing to the magazine for more than a year and lived in the greater Copenhagen area. The rate of answered questionnaires was about $30 \%$, with a higher return rate for men than women.

On the basis of these questionnaires a selection was made that aimed at representing a wide variety of age, education and vocations in the panel. And to provide an equal representation according to gender. It was however not possible to actually make this representation across gender and vocation as equal as anticipated. Both due to the larger number of men than women that answered the questionnaires and that there was an uneven distribution amongst man and women in the representation of age and education. This was due to the way the panel was generated, based on natural readers of the magazine.

The panel on whole covers ages from 15 to 70 years old. They represent variations in educational background from leaving school after the first 7 years to being a medical specialist.

\section{Narrative in Applied Communications (Popular Science)}

It is a popular assumption that narrative is a useful format for reaching a wider audience and communicating complex subjects to a naïve (in the scientific meaning) audience. (Jensen 1995, 2. udgave, 2. oplag. 1. udg. 1987) It is proposed that Illustrated Science is an example of a successful application of a genre, which involves narrative to communicate science to a wider audience.

This study undertakes to look at the relationship between narrative and cognitive aspects of the reader's perception, within an expanded view of cognition that also deals with emotive and aesthetic aspects of cognition. (Gjedde 1998) It deals with how the narrative continuum, elements depicted in the different versions interplay with the informants subjective and subliminal perceptions, as it can be seen through their retellings and the qualitative research interviews. How their narratives are constructed in their process of making meaning of the information they perceive and can be seen responded to in the retellings and interviews. How they respond to the different indicators of genre ranges from the encyclopaedic to the full narrative versions employing both narrative structure and narrative language.

Can all this be seen to influence the retellings of the informants and their comprehension and construction of meaning and credibility?

\section{Narrative, Context and Credibility for Two Readers}

\section{Background}

Hanna is a subscriber for the past 15 years. She is an old-age pensioner, 69 years old. She has a high school degree. She studied psychology at University, but did not finish it. She is the mother of seven children, and has been helping her husband with administrative duties in his business as a plumber. I do the interview with her at a table, which is cluttered 
with signs of her activities, knitting and sewing. One of her young grandchildren is running around in the room next to where we sit.

She expresses her reasons for reading the magazine like this:

\begin{abstract}
Science has to be communicated so that WE can make use of it ... the scientists should not be sitting in an ivory tower. Ordinary people also need to know. And for me personally who has a desire for knowledge STILL, for me it is rather important.
\end{abstract}

Frederik is a subscriber for the past 4 years. He is a high school graduate mathematics major, aged 19, who works in a photo-shop temporally.

$\mathrm{He}$ is still living at home with his parents in a tastefully furnished house in a nice area. His mother greets me kindly and then disappears while we sit in the kitchen.

He says about his reasons for reading the magazine:

It is obviously some rather big subjects, and [one needs] to have them condensed so that you get a good taste of it ... get an introduction to it in a non-technical way, so that it is comprehensible. If it then is something that interest you then you can go on and look for more about it, cant you? So it is like a short introduction to a lot of interesting subjects and ... comprehensible for ordinary people.

\section{The Readers Construction of Criteria for Credibility}

One of the questions in the series of semi-structured qualitative interviews was whether the informants believed the text to be credible. This question was asked to see if there was any correlation between construction of credibility and the level of narrative used. A number of different criteria for credibility emerged in response to the different articles, indicating that it is a fluid process going on between reader and text. And that the perception of topic and previous knowledge are important parameters together with the informants worldview and ideas about science.

Hanna exemplifies a number of different criteria in her responses:

To the article on astronomy, in the encyclopaedic (B) version, she responded:

Yes, with those measuring instruments they have today, I believe it is quite credible.
So she is constructing her criteria for credibility from within the scientific norms of measurability and quantification, a positivistic approach. She is advocating the mainstream scientific norms for good and credible science.

Hanna is answering the question about credibility of this full narrative version $A$ on the subject of thought-transference with a story that has a literary reference in spite of the article having no literary references. In this she is responding to the topic of the article, and possibly also to the narrative level of it, this response fits well with the theory that stories evoke more stories (Schank 1990), that they help imbed knowledge and access previous knowledge. It is a tendency in this study that the articles with a high level of narrative evoke more narrative responses.

Was it Alexander Dumas who wrote" The
Corsican Brothers" - they were twins, and one
of them became a scoundrel and the other
became a HERO, and when one of them were
wounded then the other would suffer. But
THAT was a novel. But I don't think this was
credible.

In this way she conveys that she does not find the article credible, and with a few words she evokes another genre which she think suits the topic better. This particular article did evoke vastly different responses and half the group of female readers had it as their first choice. While the other half like Hanna had it as their least preferred article.

Like Hanna Frederik also has a narrative response to the Ara in version (A) with full narrative, where he is situating the information in relation to prior relations and interests:

\begin{abstract}
When I was a young boy I had a friend who really was into biology. So we had plans about becoming marine biologists and travelling to Australia to study the parrots there and then to the Amazon and study the Ara parrots... So I do know a little about a lot of these things but I haven't really got into it in depth.
\end{abstract}

His personal narrative in response to the full narrative version is pointing to the narrative quality of the involvement of the reader, by activating similar previous knowledge. It is representative of a number of similar personal narratives produced by other informants in response to narrative or topical impulses.

The biology article on the breeding patterns of sea horses was a version $\mathbf{D}$, which was a perceived by 
Hanna as "Extremely credible". She already had extensive knowledge about this subject matter, and was able to judge the credibility by what she already knew.

The article version $\mathbf{C}$ on ornithology did she also find fully credible, it was also a subject with which she was familiar and thus capable of judging from previous knowledge. None of those evoked personal narratives that related the information to personal experiences, but a personal narrative was prompted in relation to the version $\mathrm{C}$, which has the narrative elements of emotive and imagery language.

Frederik's construction of credibility of the article about astronomy version D:

\begin{abstract}
I find it quite credible in what it says. Every time there is a statement it refers to someone who has said it ... But it still does speculate on behalf of others. Still there is something I cannot quite pinpoint. They do not present [enough] cold, cynical facts ...
\end{abstract}

So Jens has two criteria for credibility: one being that the article to be credible must present "cold and cynical facts" and one that being that it must not "speculate".

Both these criteria clashes with the narrative embedding of this material, and the more he is being reflexive about the "speculations" that are present in the article, the more his original impression of the credibility of the article is being challenged.

Frederik judges the seahorse-article in encyclopaedic (B) version to be:

\section{Rather credible because it is documented as facts ... but no sources are mentioned so it is rated as 2 (on a scale from 1-7, 1 being the highest level of credibility)}

This encyclopaedic version has "no speculations", as it has no narrative language or structure which makes him rate the article as rather credible in spite of the lack of sources.

In Frederik's criteria for credibility of the Ara in version (A) with full narrative, it is apparent that he is rating it as less credible, because of the some of the expression which he judges to be less clear and factual: "it [the article] cannot decide whether it is facts or guesswork."

So he is implying it from what he has read, which he finds sort of "trying to mystify it by being vague and then coming up with a perfectly clear explanation of the phenomena in the end"
Frederik's comments on the thought-transference article version C.: "I thought it had very low credibility. It said nothing, it seemed like just blah, blah."

He rates it very low for credibility and has the article as his second last choice - this is a pattern among all the readers that an article that is rated low for credibility is not a preferred choice, when asked to make priorities.

\section{Reading for Relevance}

The elder women (ages 52-69) are most explicit, about situating their reading in a social context they find an added dimension of meaning through what their immediate relatives, sons and daughters are interested in, adding to their own interest which are motivated by a desire for knowledge, and sometimes by special subjects like astronomy.

Most of them are not only motivated by personal interest in any subject matter, though they of course have special interests or preferred areas of knowledge. They are reading "everything", and then they are constructing relevance through the anticipated interests of the people they connect the subject matter to, when reading.

So this knowledge serves two function's - to satisfy "a desire for knowledge" and as object in communications with close relatives. And it is also through these emotional relations that they make a double sense of the material, the sense it makes for themselves and the sense they anticipate it will make for those close relations. So there is a strong element of situated cognition and of shared cognition in their reading process.

\section{Gender Differences in Narrative Preferences and Comprehension}

In order to see how the different narrative versions were being understood by the informants I have focused on their comprehension of the gist of the articles, (Schank 1990) in the analysis of their retellings of the articles.

There was generally a good comprehension of the gist of the articles, though 7 of the 16 informants did miss out on one or more of the articles. Of the nine articles they missed the gist of, 6 were encyclopaedic-versions, while there was one each of the other versions.

Of the eight women interviewed five did not comprehend the gist of one or more of the articles. These missed four encyclopaedic-versions (B), and one each of versions with narrative language but 
little narrative structure $(\mathrm{C})$ and the original version (A). The three of these articles were on astronomy, two Bs and one C. Two were B-versions of the psychological article, and one was a version A on ornithology.

Two of a group of eight men did not comprehend the gist of the articles - it was one version with little narrative language but structure (D) on psychology, and one B-version on psychology and one B-version on ornithology.

This difficulty in comprehending the gist of the encyclopaedic-versions can be due to several things. It can be the fact that the informants as subscribers are used to the magazines usual more narrative style and that the narrative elements that are thought to aid comprehension were lacking in these versions (schema-theory (Bartlett 1932, 1995; Mandler 1984). The fact that more women than men missed out on some of the articles could possibly be due to the difference in levels of education and age, since the women participants in this had a lower level of education and two were pensioners. There are however preferences in other media's (t.v. soaps, computer games) that does point in the same direction, that females have a preference for narrative.

I've previously been reporting on and discussing aspects of the gender differences. (Gjedde 1998). I've found that on a bipolar scale the female informants find the full narrative genre the most comprehensible and the encyclopaedic genre the least comprehensible. The male informants on the other hand rate the encyclopaedic versions the most comprehensible while the full narrative are rated the least comprehensible.

Since this study has been done with a limited number of informants and a complex design, that not only involve different versions but also different topics and the gender groups are varied in age and levels of education, I do not make claims for validity, that goes beyond this group of natural readers. These results do however point to interesting areas for further research in this area.

\section{Gender and Topical Preference}

Another gender specific difference emerged when the informants made choices about their preference for the different articles.

At the end of the interview the informant was asked to sort the articles hierarchically according to preference. They were posed the question "Which article do you prefer?" And then asked to put them in descending order. A pattern of gender specific preferences emerged, showing distinct differences:

The women concentrated their first choices on two of the four articles: half chose the psychology article the other half chose the astronomy article as their preferred article. And then it polarised the way that if they did not have one of these articles as their preferred article it would end up as their last choice for most of them.

The men did not polarise in that way as they made first choices among all the articles. But they did have a common choice in rating the astronomy article highly and having the article about the seahorse male giving birth as their least preferred choice. These differences were obviously topical, but on the other hand the topics were influencing the different styles of the articles, what narrative traits they acquired both in the process of being written up for the magazine, and in the process of being rewritten for this study. Again this would point to the possibility of women having different narrative preferences than men.

The two articles the females polarised around were the "softest" topic: psychology and the "hardest" topic astronomy, with the astronomy in the encyclopaedic form being the most difficult to catch the gist of.

(The concept of "soft" and "hard" topics is used by the editors of magazine in their editorial policy, for creating a balance and catering to different groups.)

\section{Strategies for Making Sense}

The informants seemed to use a number of different strategies in their reading in order to make sense of the articles. In the analysis of the retellings of the various articles and versions these strategies can be singled out:

\section{1) Appropriation of actual information:}

A) The retellings of the actual information either just mentioning facts, focusing on the actual information and rendering it as it is read.

B) Or embedding them in a story.

C) Reformatting the story, making the narrative structure more pronounced and approximating the structure to canonical oral tale structure, which example can be found represented in Labovs seminal work on oral narratives. (Labov 1967, 1997) 
2) Construction of relevance to achieve a meaningful context for narrative construction.

3) Construction of emotional and aesthetic meaning which is part of the process of narrative construction.

\section{Conclusion}

The focus of this research has been to explore the relationship between different levels of narrative within the genre of Popular Science, by presenting 4 different versions representing micro-levels of genre on a continuum ranging from encyclopaedic language to a version with narrative structure as well as imagery and emotive language in a semi-experimental design, and to explore its possible implications for the readers construction of credibility and comprehension of gist as well as looking at relevance and preference. The findings are suggesting some gender specific differences and preferences for narrative on the side of female informants, but also that topic and context may override genre and these issues would be an interesting area to further explore.

\section{Bibliography}

Bartlett, F.C. (1932, 1995) Remembering. A Study in Experimental and Social Psychology. Cambridge: Cambridge University Press.

Bettelheim, B. (1989) The Uses of Enchantment. The Meaning and Importance of Fairy Tales. New York: Vintage Books.

Branigan, E. (1992) Narrative Comprehension and Film. London: Routledge.

Franz, M.L. v. (1970) Interpretation of Fairytales. Dallas: Spring Publications.

Gjedde, L. (1998) Making Sense of Science: Experience as Cognition through the Use of Narrative in Popular Science. Paper presented at IAMCR, University of Glasgow.

Gjedde, L. (1998) Narrative Dimensions in Information Design. Info Design 98 : Information Design and the Learning Society, Cambridge 20-21 April 1998.

Gjedde, L. \& Ingemann, B. (1999) In the Beginning was the Experience. Paper presented at the $14^{\text {th }}$ Nordic Conference for Media and Communication Research. Kungälv, 14-17 August.

Greimas, A.J. (1990) Narrative Semiotics and Cognitive Discourses. London: Pinter Publishers.
The main focus has been to explore the readers criteria, strategies and preferences in relation to the varying levels of narrative, suggesting that the level of narrative does have an impact on the readers construction of credibility, and their gist comprehension and preferences. These findings are very complex, further involving the readers background and context.

Genre is seen as something not only inherent in the magazine read, but as much in the reader's relation to it and subjective perception of it. So the experience of genre can be seen as situated cognition. And the subtle perceptions of the, often mute, indicators of genre, can be explored as the filter through which narrative is perceived and constructed. Thus being an element that is actively involved in the reader's construction of meaning and expanded cognition also involving experiential qualities.

Due to the nature of this research with a complex design and a limited group of informants, its focus is more to identify areas for further research and to raise further questions than to conclusively answer them.

Huckin, et al. (1995) Genre Knowledge in Disciplinary Communication: Cogniton/Culture/Power. Hillsdale, New Jersey: Lawrence Erlbaum Associates.

Ingemann, B. (1998) Fata Morgana. Pressefotografiets virkelighed og laesernes. København: Museum Tusculanums Forlag.

Jensen, L.B. (1995) Ud af elfenbenstårnet - fortalleteknik for fagfolk der vil skrive en god historie. København: Roskilde Universitetsforlag, 2. udg., 2. oplag. (1. udg. 1987).

Labov, J.W. \& Waletzky. (1967, 1997) Narrative Analysis: Oral Versions of Personal Experience. Journal of Narrative and Life History 7(1-4): 3-39.

Mandler, J.M. (1984) Stories, Scripts and Scenes: Aspects of a Schema Theory. Hillsdale, NJ: Lawrence Erlbaum Associates.

Propp, V. (1968, 1928) Morphology of the Folktale. Austin: University of Texas Press.

Sarbin, T. (ed.) (1986) Narrative Psychology - the Storied Nature of Human Conduct. New York: Praeger.

Schank, R.C. (1990) Tell me a Story. Narrative and Intelligence. Evanston, Illinois: Northwestern University Press.

Shinn, C. a. (1985) Expository Practice. Expository Science. Whitley: Dordrecht.

The article is based on a paper presented at the seminar "Public Fact and Private Fiction? - Borderlines of Genre", University of Tampere, Department of Journalism and Mass Communication, Feb 5-6, 1999. 